\title{
Economic Evaluation of the Indoor Environmental Quality of Buildings: The Noise Pollution Effects on Housing Prices in the City of Bari (Italy)
}

\author{
Pierluigi Morano ${ }^{1}\left({ }^{\circ}\right.$, Francesco Tajani ${ }^{2}{ }^{\circ}$, Felicia Di Liddo ${ }^{1, *}$ and Michele Darò ${ }^{3}$ \\ 1 Department of Civil, Environmental, Land, Building Engineering and Chemistry (DICATECh), \\ Polytechnic University of Bari, Via Orabona 4, 70125 Bari, Italy; pierluigi.morano@poliba.it \\ 2 Department of Architecture and Design, Sapienza University of Rome, Via Flaminia 359, 00196 Rome, Italy; \\ francesco.tajani@uniroma1.it \\ 3 Mi.Da-Sound Design, Via Porro 9, 10064 Pinerolo, Italy; michele.daro@awn.it \\ * Correspondence: felicia.diliddo@poliba.it
}

check for updates

Citation: Morano, P.; Tajani, F.; Di

Liddo, F.; Darò, M. Economic

Evaluation of the Indoor

Environmental Quality of Buildings:

The Noise Pollution Effects on

Housing Prices in the City of Bari

(Italy). Buildings 2021, 11, 213.

https://doi.org/10.3390/

buildings 11050213

Academic Editors:

Alessandro Cannavale,

Francesco Martellotta and

Francesco Fiorito

Received: 5 May 2021

Accepted: 16 May 2021

Published: 19 May 2021

Publisher's Note: MDPI stays neutral with regard to jurisdictional claims in published maps and institutional affiliations.

Copyright: (c) 2021 by the authors. Licensee MDPI, Basel, Switzerland. This article is an open access article distributed under the terms and conditions of the Creative Commons Attribution (CC BY) license (https:// creativecommons.org/licenses/by/ $4.0 /)$

\begin{abstract}
Among environmental factors, noise represents one of the most relevant determinants on human health and on the urban quality level and, consequently, on real estate values. Thus, the noise pollution issue plays a significant role in public urban policies aimed at increasing the acoustic comfort level and creating more sustainable and comfortable cities. The real estate market is highly sensitive to noise factor and the residential prices can be strongly influenced by a high acoustic pollution rate. The present research aims to analyze the functional relationships between noise pollution and selling prices in four municipal areas of the city of Bari (Southern Italy). For each area, a study sample constituted by two hundred residential properties sold in 2017-2019 was detected for the identification of the main influential factors on prices and the investigation of the contribution of noise on them. The implementation of an econometric technique was used to obtain four different models (one for each municipal area of the city of Bari) able to explain the specific impact of noise pollution level on selling prices. From the comparison of the results obtained for each area, the outputs confirm the expected phenomena in terms of a decrease of noise component influence on residential prices from the central area to the peripheral. For the suburban area of the city of Bari, the model obtained does not include the noise pollution factor, showing a lower (scarce) importance of the environmental factor among the buyer and seller bargaining phases.
\end{abstract}

Keywords: noise pollution; environmental factors; property prices; genetic algorithm; residential market

\section{Introduction}

Noise is one of the most significant environmental risks to health. It continues to be a growing question of concern discussed by policy decision-makers. Road traffic, public transportation systems, workplaces, industrial machinery, loud music and electronic equipment have a relevant impact on people's well-being. The correlations between some pathologies and the continuous exposure to the physical agent of noise are known; in the context of health protection in the workplace, for example, there have been specific laws and procedures that regulate the exposu1re of workers to noise, identifying limits of level and exposure time, and in some cases, suitable personal protective equipment to protect hearing. In the context of traffic noise, the Environmental Noise Directive of the European Union [1] is focused on the noise generated by this source and defines the assessment threshold; currently, at least 100 million EU people are affected by traffic noise.

Especially in urban areas, there are also additional sources of noise that weigh on the population, such as anthropic noise in crowded places and the so-called "nightlife" noise. This type of noise occurs in a punctual way around aggregation centers and changes during the day, avoiding analysis on the incidence when referring to large populations. 
Sound emission becomes noise when it produces negative effects on the environment and on human health, that is, when it compromises quality of life.

Noise pollution, like air pollution, "directly" affects health [2-4], differing from water and soil pollution which damage the health only if water or soil products are used for food production.

In recent decades, European technological development has led to several lifestyle changes that have effects on urban systems. At the same time, appropriate measures aimed to reduce the noise of the working and home environment and to fully preserve the life quality level have not been adopted in all countries because of the high costs connected to the interventions for the introduction of acoustic isolation systems (acoustic glazing and acoustic window and façade units, as well as internal sound-insulating partitions).

Moreover, the economic influence of noise is growing. The World Health Organization (WHO) estimates that, as of 2012, at least 1.6 million healthy life years in Western Europe were being lost annually to environmental noise [5]. Other assessments put the external noise cost related to health issues between $0.3-0.4 \%$ of GDP in the European Union $[6,7]$ and $0.2 \%$ of GDP in Japan [8]. Long-term exposure to noise has been shown to cause 12,000 premature deaths and contribute to 48,000 new cases of ischemic heart disease per year in Europe. Furthermore, it is estimated that 22 million people are affected by chronic discomfort and 6.5 million people are affected by chronic sleep disturbances [9].

The WHO Regional Office for Europe has developed noise guidelines [10] for (i) the definition of the noise level that causes significant harmful effects on health and must not be exceeded, (ii) the identification of the measures to reduce its effects as much as possible. The document constitutes an important reference for political decision-makers and expert technicians for law development in order to regulate the noise issue at local, national and international levels. The guidelines aim to raise awareness the public administrations and private investors of the harmful impacts on the local community, influencing urban planning choices to achieve the Goals of the Agenda 2030 for Sustainable Development [11] In particular, the noise protection contributes to the achievement of (i) Goal 3 "Ensure healthy lives and promote well-being for all at all ages," as the noise exposure is a significant cause of health deterioration, (ii) Goal 9 "Build resilient infrastructure, promote inclusive and sustainable industrialization and foster innovation" through the development of low-cost sensors (MEMS (Micro Electro-Mechanical Systems) microphones) which, combined with the increase in the transmission and management of large amounts of data, could be an incentive to create widespread acoustic monitoring networks, (iii) Goal 11 "Make cities and human settlements inclusive, safe, resilient and sustainable," as the progressive expansion of the population in urban agglomerations determines an increase in the demand for mobility and an increase in social and entertainment activities, potentially causing disturbance.

The Directive 2002/49/EC [1] modifies the methods of assessing the harmful effects of noise pollution, taking into account: (i) ischemic heart disease; (ii) high annoyance; (iii) high sleep disturbance.

The adverse effects are separately calculated using the relative (or absolute) risk formulas and they must be independently assessed for each noise source. Currently, road, rail and airport traffic are only considered, and Member States are required to transpose the new Directive by 31 December 2021.

In the framework outlined, different studies in the U.S. and Europe have demonstrated the relationship between real estate markets and environmental noise, showing a decrease of housing prices per decibel $(\mathrm{dB})$ of noise increase.

This approach has limitations, as the "noise level" parameter alone does not consider the typology and specific factors of the individual sources, but it can provide a first indication about the correlation between housing price and the quality of the acoustic environment.

Regarding the disturbance generated by multiple types of anthropic activities that are different from industrial noise and traffic noise, there are greater difficulties in fram- 
ing the issue in a generalizable perspective, especially in urban areas, and therefore the definition of universally feasible strategies and solutions is more complex. The harmful noise, connoted as neighborhood disturbance, often derives from (i) discos, (ii) bars and squares frequented by young people and (iii) productive or commercial activities located in residential contexts. These sources are randomly distributed throughout the territory and they are sometimes concentrated in areas with particular vocations, such as the so-called nightlife "movida" which, on certain days and times, upsets the acoustic environment of a residential area. The "movida" noise originates from a plurality of sources, sometimes fixed, but often linked to the anthropic emissions of subjects which can be assimilated to punctual, temporary and mobile sound sources. The difficulty in determining and quantifying the disturbance generated by this type of noise makes it complicated to circumscribe and summarize in coherent data that can be suitable for correlation with others. In this sense, the different connotation given to the voices and bawl that are considered "festive" in a holiday location but "unbearable" if they are under the home windows should be taken into account. Therefore, it is difficult to correlate this type of environmental noise with its effects on property values. Furthermore, it should be added that the noise sources are often concentrated around an attraction pole, for example a bar, which can also be isolated and located in an acoustically quiet context. This determines an excess of noise that could literally cause the collapse of the market prices of the residential units located in its immediate closeness; on the other hand, this "disturbance" is only limited, as at a distance of a few tens of meters the situation varies and the property values are consistent with the area average values. In this sense, the discrimination of the entity and reliability of an economic indicator that takes into account specific elements is a complex operation.

Moreover, robust and extended data able to allow a first-level study of the correlation between environmental noise and property prices by focusing on traffic-induced noise are known:

1. The noise caused by traffic on infrastructures, in particular in urban areas, determines the highest impact on the population, both in quantitative terms and regarding the exposure.

2. European and national directives consider as a first priority the analysis, the mapping, the monitoring and the mitigation of transport infrastructures: this allows for immediate and updated availability of studies and checking data.

3. The "traffic" source is generated by vehicles (or trains) that move on predetermined and fixed paths (and in this way, to a certain extent, for aircraft). Therefore, this source is acoustically comparable to a linear-type source whose emission levels are directly proportional (i) to the number of vehicles in transit (i.e., vehicles/hour), (ii) to the average travel speed and (iii) to the percentage of heavy vehicles (or freight trains). Once a road axis has been acoustically characterized, it knows with good approximation the values of sound emission (and the consequent input at the receivers) by monitoring one or more correlated parameters (e.g., the number of transits).

4. The "length" of a road axis can be considered as a single homogeneous "traffic" source involving multiple properties, such as in an urban area where a stretch of road defined by typical acoustic factors has a minimum length equal to one block of properties. The road stretches with almost homogeneous traffic conditions, which determine the typical sound emission, are generally much longer and cross entire neighborhoods.

5. The vehicular traffic, as well as air and rail traffic, presents considerable differences in noise emissions between the day and night, allowing the influence of the exposure to noise phenomena for the residential units in the night period (where a sleep disturbance can occur) on the property market to be analyzed compared to the more relevant, but less complained about daytime disturbance.

\section{Aim}

The present research concerns the analysis of the influence of noise pollution, generally defined by the traffic on road infrastructure, on housing prices in the city of Bari (Southern 
Italy). With reference to the four municipal areas in which the territorial context is divided, taking into account the geographical distribution developed by the Real Estate Market Observatory (OMI) of the Italian Revenue Agency [12], a study sample relating to two hundred properties sold in 2017-2019 for each area was considered. For each sample, the total market prices and the relevant influential factors for their formation were detected in order to assess the contribution of acoustic component on the local residential market. The implementation of an econometric technique allowed for obtaining four models (one for each municipal OMI area of the city of Bari) able to point out the functional relationships between the most influential factors selected and the selling prices. The study aims to examine the contribution of sound level calculated in the street where each property is located on the housing prices in order to (i) investigate the influence of noise pollution in each municipal OMI area of the city of Bari considering the homogeneous noise factors on the road axes considered; and (ii) compare the outputs obtained for defining the different impacts on residential market segments in the city.

This work is part of a wider research line aimed to assess the externalities deriving from different sound levels that characterize the acoustic environment of the different areas in terms of housing prices. The results could represent a useful tool for urban planning to guide the decision-making processes towards public strategic actions able to reduce noise pollution levels. In fact, the output of the analysis could constitute a reference for Public Administrations for orienting local initiatives aimed to decrease the noise pollution level and, in this way, to improve environmental quality in the city. In this sense, this research intends to highlight the benefits for the community from a decrease of noise pollution levels in terms of well-being and the economy. Firstly, it is well known that the main positive impact of living in a noiseless and acoustically comfortable environment is connected to human health. Secondly, from the economic point of view, the increase of the existing residential asset market value is strongly linked to housing factors, among which the acoustic comfort constitutes a fundamental factor for the reference market appreciation and the buyers' decisions.

Furthermore, in the contexts of civil trials, the practical outcome of the analysis could be a significant reference for experts to define the loss of property value caused by long exposure to noise; therefore, this work intends to provide appropriate indications, including charts, in order to support the official technical consultants with acoustic damage assessments.

The structure of the paper is summarized as follows. In Reference Literature (Section 3), the main international and national research that have examined the relationships between noise pollution and property prices are illustrated. In Case Study (Section 4), the application is introduced: the variables considered are listed and the main descriptive statistics related to the four study samples are analyzed. In Methodology (Section 5), the technique implemented and the model obtained for each study sample is explained. In particular, the specific statistic performances are reported, the empirical reliability of the functional correlations is checked, and the results are discussed. Finally, in Conclusions (Section 6), the findings of the work are outlined.

\section{Reference Literature}

A high noise pollution level has a relevant impact on rents, costs and values of residential properties. Among the factors taken into account in the choice processes (architectural aspects, distribution of internal spaces, quality of the materials used, thermal insulation, etc.), the acoustic comfort level constitutes an important element considered by buyers and sellers relating to house sales.

In this sense, the noise pollution is an essential indicator in the environmental quality definition that, in turn, influences the property's market value, as it could indicate the occurrence of a noise nuisance negatively impacting social relationships and people's well-being. The building's acoustic comfort depends on different factors: some of them are immediately perceived, e.g., the road traffic exposure, the proximity to airports or railway, 
the presence of industrial areas or commercial and recreational activities (restaurants or public places or clubs open until late at night, etc.), others are more "hidden" and are related to the building construction techniques, materials and technologies.

In recent years, new needs and services has led a continuous growth of the noise pollution level: the buildings are "invaded" by internal and external sound that generates sleeping and working disorders. The noise, in fact, determines health problems-widely documented in the reference literature $[13,14]$-including annoyance, tiredness, headache, anxiety and physiological and even cardiovascular stress effects. In this context, the inclusion of a property in an acoustically degraded area or with a lack of sound insulation can cause a depreciation of the property. It has been noted that a house or an office placed in a noisy environment has less market value compared to the same one, ceteris paribus, located in a peaceful and noiseless place.

With reference to the property acoustic quality, it is linked to (i) the acoustic insulation of both the internal and external dividing walls and of horizontal partitions that can be obtained through the introduction of acoustically performing materials and by adopting adequate technical solutions; (ii) the footfall sound insulation, which can be obtained through floating or resilient floors; (iii) the low emission level of sewage systems, which can be obtained through appropriate installation measures and choice of low intrinsic noise solutions; (iv) the airborne and structural noise of systems such as lift, heating, autoclaves, etc.; (v) the replacement of older paved roads with smoother asphalt; and (vi) a better management of traffic flows and the introduction of speed limits in urban contexts. Furthermore, in recent years strategic measures aimed at raising the awareness of people to change their behavior to use less noisy transport modes, e.g., cycling, walking or electric vehicles, have been promoted in several cities.

The correlations between noise pollution factors and housing prices have been studied in numerous research papers [15-28]. All the developed analyses intend to highlight the fundamental role played by the acoustic component on selling prices. Chang and Kim [29] demonstrated a drop in prices equal about to $0.5 \%$ per additional decibel emitted by the rail network in the city of Seoul (Korea). Furthermore, Bureau and Glachant [30] have shown that the selling prices of the residential units located in peaceful districts of the city of Paris (France) are 1.5\% higher than those of properties in noisier areas. Similarly, the European Environment Agency have attested to a price decrease in the range of 0.2-1.5\% for each decibel above 50-55 dB [31].

The analysis of the road noise influence on the prices of condominiums in the city of Hamburg (Germany) represents the main goal of Brandt and Maennig's research: on the basis of micro-level datasets capturing road traffic-noise exposure, price discounts in the amount of $0.23 \%$ following a $1 \mathrm{~dB}(\mathrm{~A})$ increase in road noise were observed [32]. Most studies aimed to monetize noise have focused on road and air noise [33-38]. Andersson et al. [39] examined the market participants' preferences regarding improvements in environmental quality through the willingness to pay to reduce road and railway noise.

With reference to 292 single-family houses located in a suburb of the city of Stockholm, the empirical analysis carried out by Wilhelmsson [40] found an average noise discount of $0.6 \%$ of the house price per decibel, or a total discount of $30 \%$ of the price for a house in a noisy location compared to a house in a quiet one.

In the last decades, a steady growth in road traffic intensity in most urban areas has forced politicians and city planners to seriously consider the resulting environmental impact, such as traffic noise. The assessment of negative factors related to acoustic component is required in order to reveal the social benefit of infrastructure plans and to orient the public decisions toward efficient strategies to decrease noise pollution. For the Copenhagen region, Rich and Nielsen [41] analyzed the implicit costs of traffic noise, measured as the marginal percentage loss in property values with respect to the decibel traffic noise, highlighting a Noise Sensitivity Depreciation Index (NSDI)—defined as the marginal percentage depreciation in house prices with respect to $\mathrm{dB}$ noise- of 0.54 for houses and 0.47 for apartments. Some years later, Duarte and Tamez [42] demonstrated that 
the environmental noise has become a major issue in densely urbanized areas, defining a NDSI equal to $0.08 \%$ by differentiating according to city areas and to the nature of the noise source. The outputs obtained by Wen et al. [43] and based on data of 7590 multi-story and 4980 high-rise residential properties in the city of Hangzhou (China) in 2017 attested that the urban road traffic generates noise and air pollution, thereby resulting in a disamenity effect on surrounding residential property and subsequently affecting the willingness to pay from homebuyers. The results confirmed a significant moderating effect of floor level on the impact of road traffic.

In order to identify the relationships between traffic noise levels and the prices of apartments located in three residential districts in the city of Olsztyn in north-eastern Poland, Szczepańska et al. [44] implemented a linear correlation analysis. The negative relationship obtained confirms that a building's location relative to the road network and, consequently, the level of traffic noise, is one of the most significant factors in the potential real estate buyers' choice of property.

The functional link between rental prices and noise levels in the city of Munich (Germany) was determined with the implementation of the hedonic price regression model in the studies of Kuehnel and Moeckel [45]. In particular, the output indicated a rental price discount equal to $0.4 \%$ per $\mathrm{dB}(\mathrm{A})$, on average. Similar negative correlations between housing prices and noise levels have been reported by other authors [46-48].

In the framework outlined, the present research analyzes the correlations between the noise pollution and the housing prices in a city located in the Southern Italy. Compared to similar research in international and national contexts, this aim was carried out by borrowing (i) the urban acoustic maps developed by an Italian public entity, (ii) the classification of the sound pressure level through different acoustic ratings and (iii) an econometric technique that implements a genetic algorithm for the assessment of the contribution of the influential factors on selling prices.

\section{Case Study}

This case study concerns four samples of two hundred residential properties located in the city of Bari (Italy). Bari is the main city of the Apulia region in Southern Italy. It covers an area of about $120 \mathrm{~km}^{2}$ and it has a population of over 325,000 inhabitants.

Each residential unit of the four study samples had been sold between the second half of 2017 and the first half of 2019 and is located in one of the four municipal areas of the city of Bari, taking into account the geographical distribution developed by OMI of the Italian Revenue Agency. In particular, the definition provided by OMI of the municipal trade areas is the following: "Aggregation of homogeneous contiguous zones. It represents a territorial area with specific geographical position, and it reflects a consolidated urbanistic location. The municipal context is divided into the following OMI areas: central, semi-central, peripheral, suburban, extraurban".

The central area identifies the municipality portion corresponding to the city urban center, i.e., the distinguishable building aggregate able to attract a larger settlement. The semi-central area identifies the municipal zone immediately adjacent to the city urban center and directly connected to it for services, transport system, infrastructure. This area presupposes the presence of the central and peripheral ones, being located between the two. Therefore, the peripheral area identifies the portion of the municipal territory that is bound by built settlement external limiting. The suburban area indicates the territory zone with the urbanized portions separated from the urban agglomeration from an undeveloped area, i.e., a natural or artificial barrier. The extra-urban area represents the municipal zone where the main activity is agricultural with rural buildings or where the residential properties are almost or completely absent. In this sense, the extra-urban area identifies the remaining part of the municipal context not included in the previous areas and it is bound by the administrative city border; therefore, it is one residual municipal region [49].

With reference to medium-sized municipalities, the following areas are normally identified: old town and central zones (OMI central area), city semi-central zones (OMI 
semi-central area), residential expansion zones and artisan-industrial zones (OMI peripheral and/or suburban area), agricultural and rural zones (OMI extra-urban area). Each of the municipal areas may require an articulation in multiple different areas.

For the present analysis, OMI areas considered were the central, the semi-central, the peripheral and the suburban. The extra-urban area was excluded as the building is scarcely present or mainly rural.

For each property considered in the analysis, the selling price and the most influential intrinsic and extrinsic characteristics taken into account by buyers and sellers in the negotiation phases were considered. With reference to the indications provided by the market operators in the four municipal OMI areas of the city of Bari, the influential factors in the corresponding market segment of each property were analyzed. Figures 1-4 show the localization of the four study samples in the related municipal OMI areas of the city of Bari. In Figure 5, the localization of the eight hundred properties considered for the case study in the entire municipal territorial context of the city of Bari is reported.

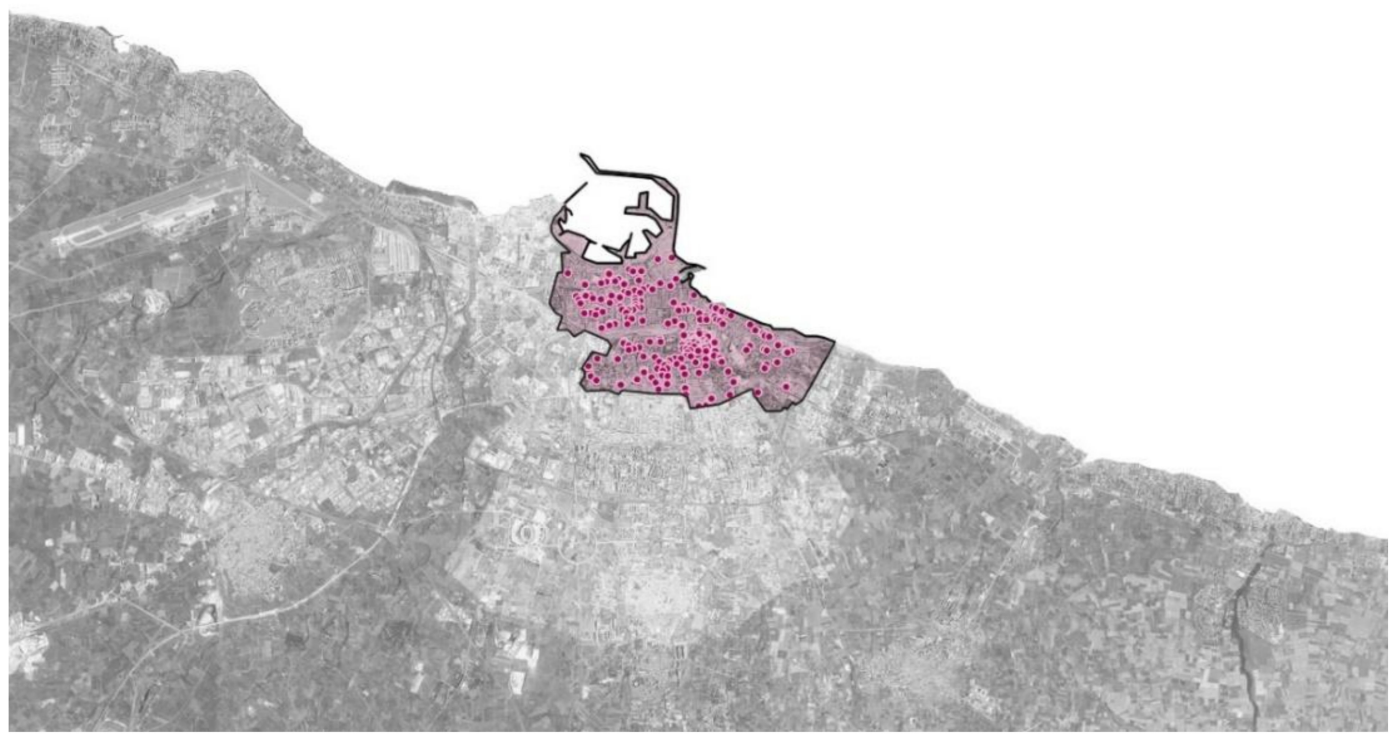

Figure 1. Localization of the study sample properties in the OMI central area of the city of Bari.

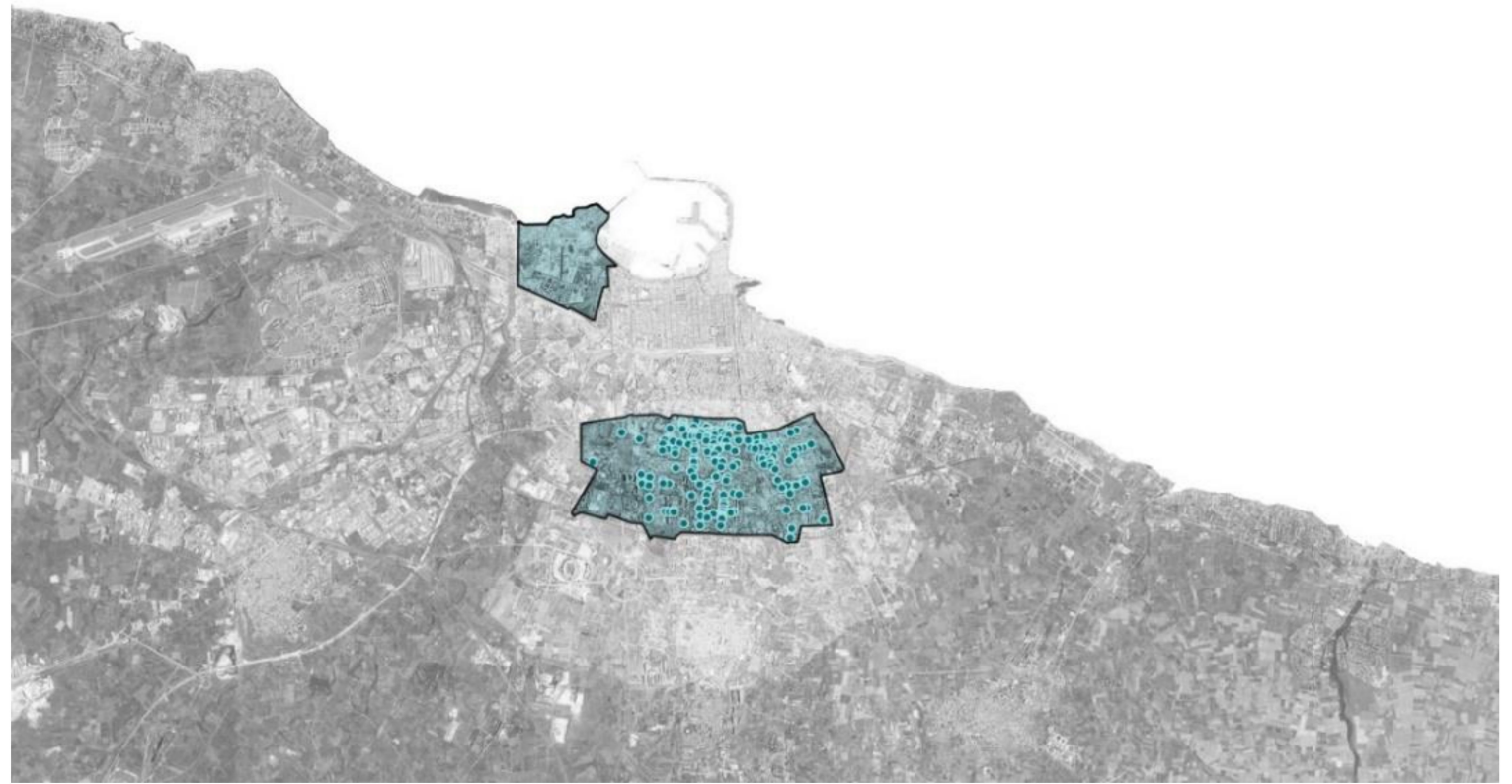

Figure 2. Localization of the study sample properties in the OMI semi-central area of the city of Bari. 


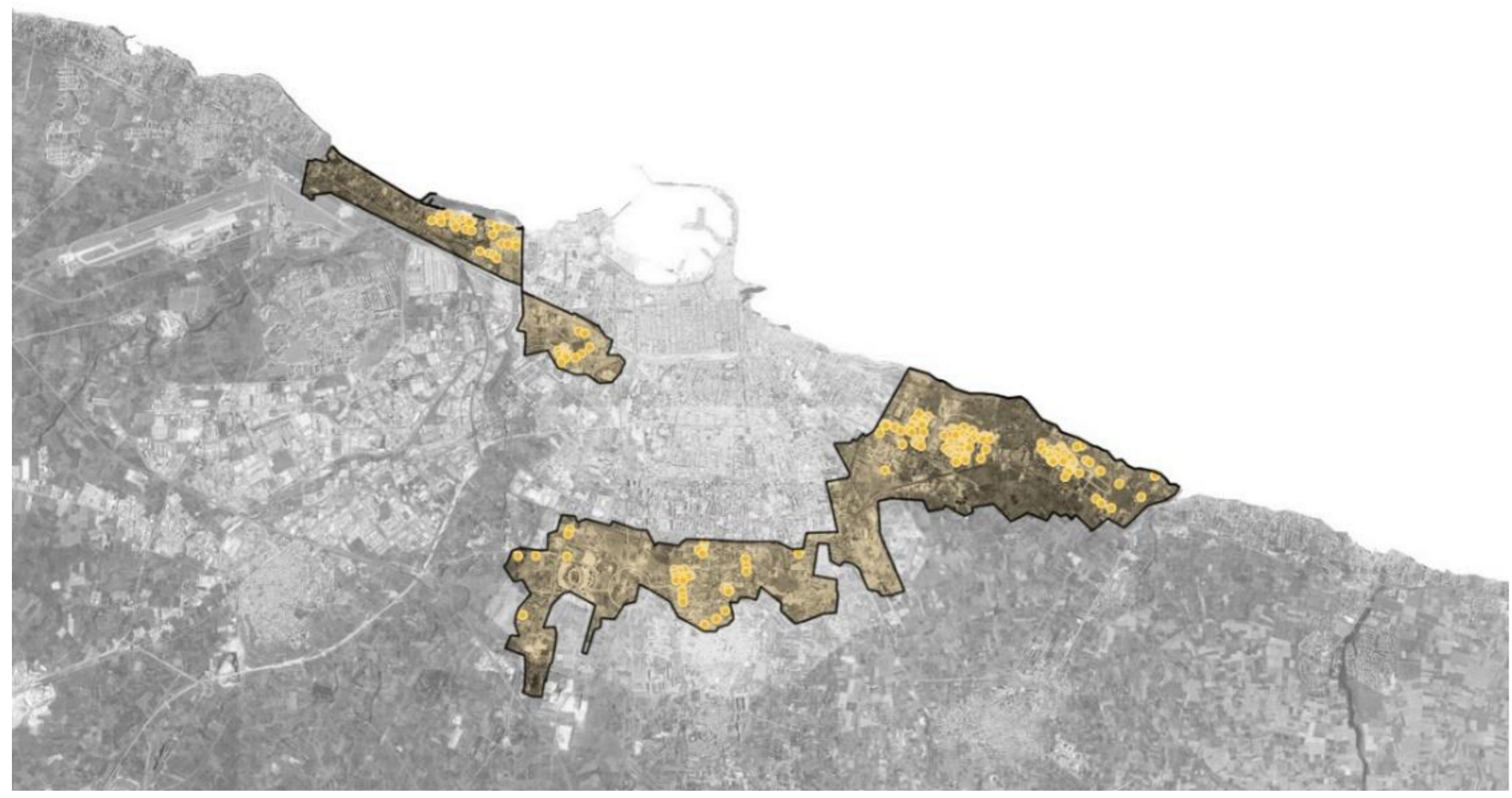

Figure 3. Localization of the study sample properties in the OMI peripheral area of the city of Bari.

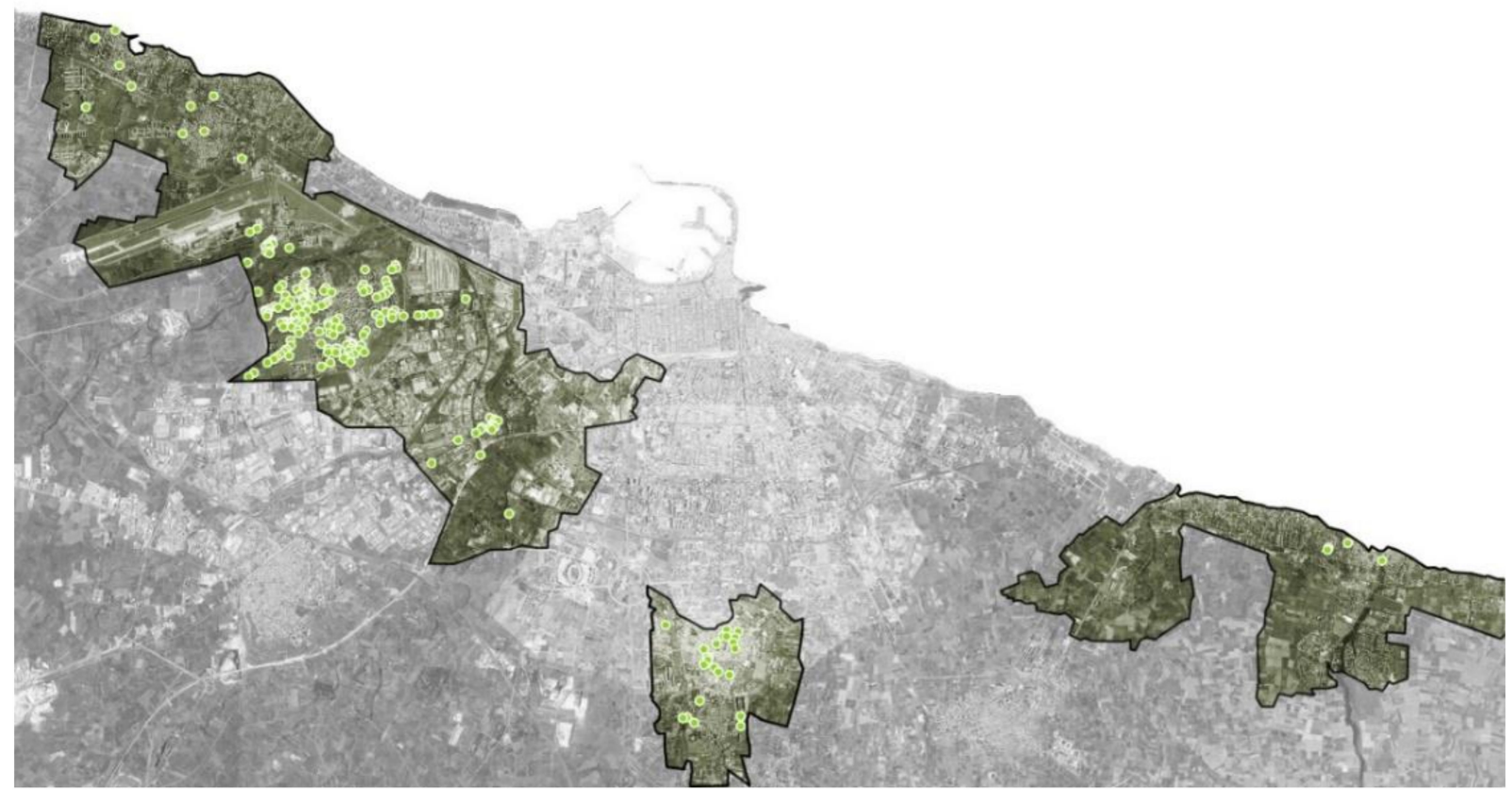

Figure 4. Localization of the study sample properties in the OMI suburban area of the city of Bari. 


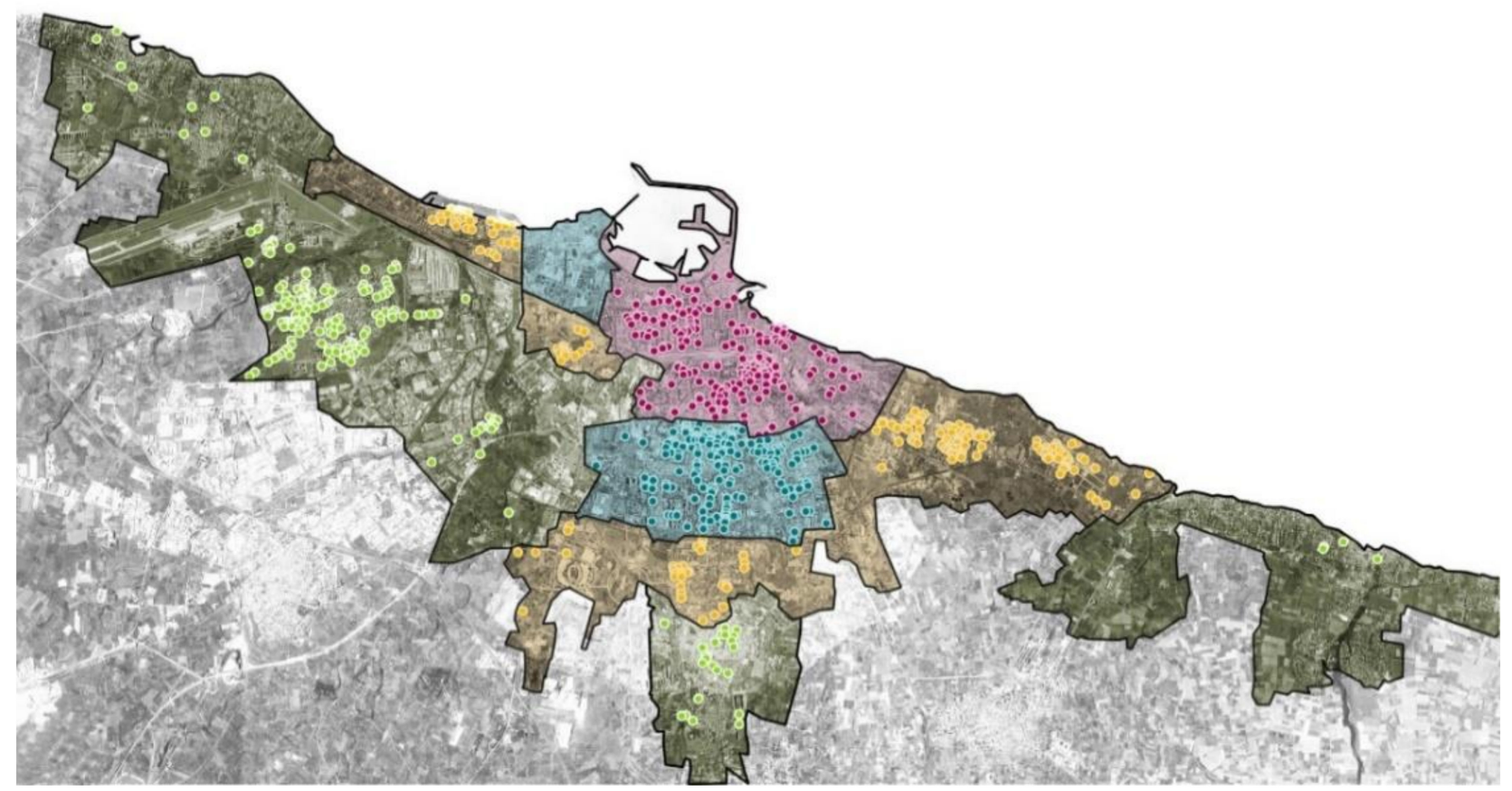

Figure 5. Localization of the study sample properties in the city of Bari.

Variables

With reference to the model developed in this research, the dependent variable is represented by the total selling price (Pr), expressed in euro. For each residential unit, the factors considered by local operators—buyers and sellers—in the bargaining phases [50] were detected. In particular, the variables were selected on the basis of (i) the indications given by the market operators in the area, (ii) the data generated by OMI and (iii) research found in the reference literature [51-54]. In fact, several scientific papers pointed out the unavoidable tradeoff between bias from omitted factors and increased sampling variance related to the collinearity that is involved in this step [55], even if a relative agreement on the major influencing factors is observed [56-58].

Among the variables analyzed, the acoustic one selected by local real estate agents confirms the importance assumed by this factor in the context of the Italian market. The recent fiscal incentive measures taken within the residential asset redevelopment and ex-novo realizations framework aim to enhance the housing comfort improvement and, generally, to reach a high housing quality.

The explanatory variables considered are described below:

- $\quad$ the size of the property (S) in square meters of gross floor area;

- $\quad$ the number of bathrooms in the property (B);

- $\quad$ the floor level on which the property is located (L);

- the presence of the lift in the building where the property is located (A). In the model, the factor is considered as a dummy variable, for which the presence of the service is represented by the value "one," whereas the absence of the service is indicated with the value "zero";

- $\quad$ the presence of the parking space in the building where the property is situated $(\mathrm{P})$;

- the maintenance conditions of the property (Sc), assumed as a qualitative variable and differentiated, through a synthetic evaluation, by the scores 1, 3 and 5, respectively corresponding to the categories "to be restructured," "fit for habitation" and "restructured." Following the logic of the dummy variables, the score "one" is assigned to the category that defines the specific quality of each property, and the score "zero" for the remaining two categories. In particular, the "to be restructured" state refers to properties that require significant refurbishment interventions, because the functionality and the livability of the property are not good due to the inappropriate conservative state 
of the elements that compose it; the "good" state indicates properties whose maintenance conditions are acceptable and whose functions can be carried out without heavy refurbishment interventions. Finally, the "excellent" state refers to properties characterized by high construction and aesthetic quality, possibly affected by recent redevelopment and renovation initiatives;

- $\quad$ the distance of the property from the Araldo di Crollalanza waterfront of the city of Bari (Dl), identified as the landmark for the local community, according to different surveys carried out. The variable is measured in kilometers it takes to walk to it;

- $\quad$ the maintenance conditions of the public spaces adjacent to the property (Sa), assessed through a scale of scores $(1,3,5)$ attributed by panels of experts (sociologists, landscape architects, etc.), where the score " 1 " indicates a bad maintenance condition of the public spaces, the score " 3 " is a good state and the score " 5 " is an excellent state. In particular, fixed furniture suitable for equipping public spaces, such as public lighting lamps, waste baskets, benches, planters, parking canopies, display boards for billboards, etc., are included in the category of street furniture;

- $\quad$ the property distance from the nearest food market or grocery shop (Dm), calculated in kilometers it takes to walk to it. The category "grocery shop" includes the self-service retail shops of consumer products (supermarkets and hypermarkets) present in the municipal area;

- the maintenance conditions of the building facades adjacent to the property (Sf), assessed through a scale of scores $(1,3,5)$ attributed by panels of experts (sociologists, landscape architects, etc.): the score "1" indicates bad maintenance conditions of the facades" conservative state, the score " 3 " is a good state and the score " 5 " is an excellent state.

- $\quad$ the road private and public vehicular traffic (buses) level (T), evaluated by a team of experts (sociologists, landscapers, architects, engineers, etc.) through a scale of scores defined as follows: score " 1 " indicates a road characterized by high traffic intensity, score " 3 " indicates a medium traffic intensity, score " 5 " indicates a road characterized by low traffic congestion;

- $\quad$ the property distance from the nearest public green space (Dv), calculated in the kilometers it takes to walk to it;

- $\quad$ the property distance from the nearest highway (Dt), measured in the kilometers it takes to get there by car;

- $\quad$ the distance of the property from the nearest railway station (Ds), measured in the kilometers it takes to walk to it;

- $\quad$ the perceived environmental quality level of the property area (Qn), assessed by assigning a numerical score from " 1 " (disagreement with the item) to " 5 " (agreement with the item), given by a sample of users sufficiently representative of the urban area. The items considered are:

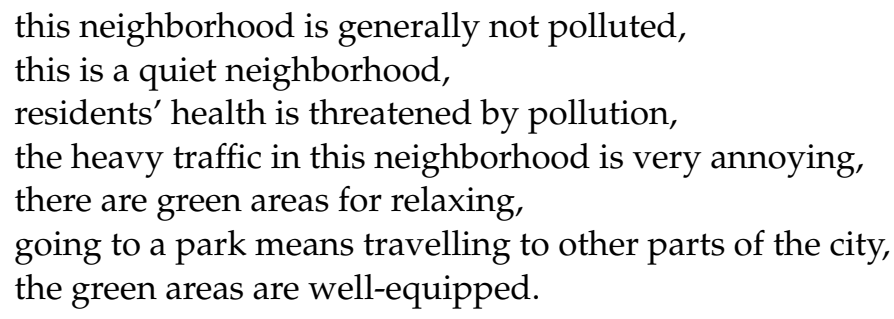

- $\quad$ the sound level (Ld), expressed in decibels $\mathrm{dB}(\mathrm{A})$, measured on day, evening and night intervals, in the street where the residential unit is located. The data are borrowed by the Strategic Noise Map of the Bari agglomeration, published in June 2017 by the Scientific Directorate of the Regional Agency for Environmental Prevention and Protection of the Puglia Region (ARPA Puglia) and reported in Figure 6 [59]. The sound pressure level expressed in decibels are shown in the map for each city road axis and it is divided into seven classes of ratings as follows:

$$
\text { Rating 1: } \leq 40 \mathrm{~dB}(\mathrm{~A}) \text {; }
$$


(ii) Rating 2: $>40 \mathrm{~dB}(\mathrm{~A})$ and $\leq 50 \mathrm{~dB}(\mathrm{~A})$;

(iii) Rating 3: $>50 \mathrm{~dB}(\mathrm{~A})$ and $\leq 55 \mathrm{~dB}(\mathrm{~A})$;

(iv) Rating 4: $>55 \mathrm{~dB}(\mathrm{~A})$ and $\leq 60 \mathrm{~dB}(\mathrm{~A})$;

(v) Rating 5: $>60 \mathrm{~dB}(\mathrm{~A})$ and $\leq 65 \mathrm{~dB}(\mathrm{~A})$;

(vi) Rating 6: $>65 \mathrm{~dB}(\mathrm{~A})$ and $\leq 70 \mathrm{~dB}(\mathrm{~A})$;

(vii) Rating 7: $>70 \mathrm{~dB}(\mathrm{~A})$ and $\leq 75 \mathrm{~dB}(\mathrm{~A})$.

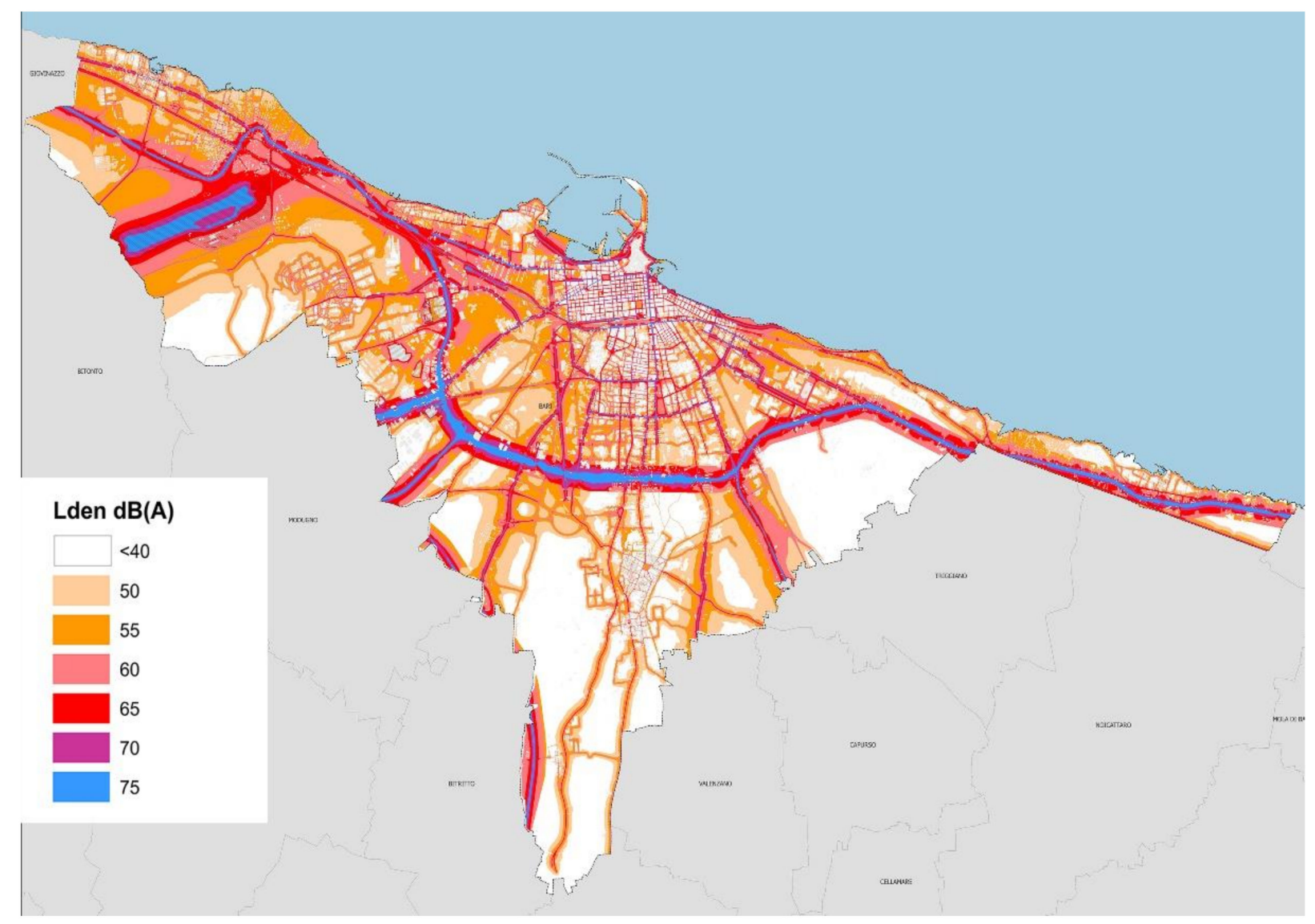

Figure 6. Strategic Noise Map of the city of Bari (Source: Arpa Puglia—Scientific Directorate, adapted from ref. [59]).

It should be noted that some variables considered in the present research are directly or indirectly connected to the noise and to its effects on selling prices. In this sense, the floor level on which the property is located may influence the acoustic pollution, as the road traffic or leisure activity noises are mainly perceived on lower floors. Furthermore, the presence of the parking spaces in the building where the property is located might cause different noise sources, e.g., a car's engine or horn. At the same time, the property distance from the nearest railway station or from the nearest highway influences the noise pollution level since there are different noisy elements that characterize these places, e.g., the trains' passage or the announcements for the trains' information or, in the case of highway proximity, the traffic congestion. It is evident that the variable "road, private and public vehicular traffic (buses) level of the building area" is strongly linked to the noise pollution level recorded for each property, as the vehicular traffic is one of the most relevant noise sources. Finally, it is expected that the maintenance conditions of the property have an impact on selling prices, as an "excellent" state presupposes recent refurbishment initiatives, e.g., the realization of acoustic insulation interventions. Contrarily, the "to be restructured" state is reserved for properties that are characterized by bad maintenance conditions and require significant refurbishment interventions, among which acoustic improvement operations are included. 
The data, i.e., the values of the selected explanatory variables relating to each property of the four study samples, were subsequently homogenized through a normalization operation in order to obtain numerical terms of the same size order and to facilitate the comparison between them.

In Table 1, a summary of the variables considered in the analysis is shown. The acronym, the type (dummy or cardinal or discrete) and the measurement unit for each variable is specified.

Table 1. Summary of the variables selected in the analysis.

\begin{tabular}{|c|c|c|c|}
\hline Variable & Acronym & Typology & Measurement Unit \\
\hline Total selling price & $\operatorname{Pr}$ & Cardinal & $€$ \\
\hline Size & S & Cardinal & $\mathrm{m}^{2}$ \\
\hline Bathroom number & B & Cardinal & number \\
\hline Floor level on which the property is located & $\mathrm{L}$ & Cardinal & number \\
\hline Presence of the lift in the building where the property is located & A & Dummy & 1 -presence, 0 -absence \\
\hline $\begin{array}{l}\text { Presence of the parking space in the building where the } \\
\text { property is located }\end{array}$ & $\mathrm{P}$ & Dummy & 1 -presence, 0 -absence \\
\hline Quality of the property maintenance conditions & Sc & Discrete & $\begin{array}{c}\text { 1-"to be restructured" property, 3-“fit for } \\
\text { habitation" property, } \\
\text { 5-"restructured" property. }\end{array}$ \\
\hline $\begin{array}{l}\text { Property distance from the Araldo di Crollalanza waterfront of } \\
\text { the city of Bari }\end{array}$ & $\mathrm{Dl}$ & Cardinal & kilometers by walking \\
\hline $\begin{array}{l}\text { Maintenance conditions of the public spaces adjacent to the } \\
\text { property }\end{array}$ & Sa & Discrete & $\begin{array}{c}\text { 1-bad maintenance, } \\
\text { 3-good state, 5-excellent state. }\end{array}$ \\
\hline Property distance from the nearest food market or grocery shop & $\mathrm{Dm}$ & Cardinal & Kilometers by walking \\
\hline $\begin{array}{l}\text { Maintenance conditions of the building facades adjacent to the } \\
\text { property }\end{array}$ & Sf & Discrete & $\begin{array}{c}\text { 1-bad maintenance, } \\
\text { 3-good state, 5-excellent state. }\end{array}$ \\
\hline $\begin{array}{l}\text { Road, private and public vehicular traffic (buses) level of the } \\
\text { building area }\end{array}$ & $\mathrm{T}$ & Discrete & $\begin{array}{c}\text { 1-high traffic intensity, 3-medium traffic } \\
\text { intensity, } \\
\text { 5-low traffic congestion }\end{array}$ \\
\hline Property distance from the nearest public green space & Dv & Cardinal & Kilometers by walking \\
\hline Distance from the nearest highway & Dt & Cardinal & Kilometers by car \\
\hline Distance from the nearest railway station & Ds & Cardinal & Kilometers by walking \\
\hline Perceived environmental quality level of the property area & Qn & Discrete & $\begin{array}{l}\text { Scores scale from } 1 \text {-disagreement with the } \\
\text { item to 5-agreement with the item }\end{array}$ \\
\hline Sound level in the street where the property is located & Ld & Discrete & $\begin{array}{l}\text { Rating 1: } \leq 40 \mathrm{~dB}(\mathrm{~A}) \text {; } \\
\text { Rating 2: }>40 \mathrm{~dB}(\mathrm{~A}) \text { and } \leq 50 \mathrm{~dB}(\mathrm{~A}) \text {; } \\
\text { Rating 3: }>50 \mathrm{~dB}(\mathrm{~A}) \text { and } \leq 55 \mathrm{~dB}(\mathrm{~A}) \text {; } \\
\text { Rating 4: }>55 \mathrm{~dB}(\mathrm{~A}) \text { and } \leq 60 \mathrm{~dB}(\mathrm{~A}) \text {; } \\
\text { Rating 5: }>60 \mathrm{~dB}(\mathrm{~A}) \text { and } \leq 65 \mathrm{~dB}(\mathrm{~A}) \text {; } \\
\text { Rating 6: }>65 \mathrm{~dB}(\mathrm{~A}) \text { and } \leq 70 \mathrm{~dB}(\mathrm{~A}) \text {; } \\
\text { Rating 7: }>70 \mathrm{~dB}(\mathrm{~A}) \text { and } \leq 75 \mathrm{~dB}(\mathrm{~A}) \text {. }\end{array}$ \\
\hline
\end{tabular}

Tables S1-S4 in Supplementary Materials report the main descriptive statistics of the selling prices and values of the explanatory variables for the four municipal OMI areas of the city of Bari. The analysis has allowed a global reading of the phenomenon through the chosen samples. For each characteristic, the recorded average value, the standard deviation, the different levels or intervals that each variable can be divided into and the frequencies with which each is verified for the properties of the study samples are indicated.

\section{Methodology}

The methodologic approach used is the Evolutionary Polynomial Regression (EPR). In particular, a recent version of EPR [60], called EPR-MOGA, was implemented. The EPRMOGA applies a multi-objective evolutionary genetic algorithm as an optimization strategy based on the Pareto frontier and it allows to simultaneously reach different objective 
functions, such as to define an optimal Pareto frontier of the fixed conflictual objectives that provide for (i) the maximization of the statistical model accuracy; (ii) the maximization of the model parsimony, by means the minimization of the number of coefficients $\left(a_{i}\right)$ of the equation; (iii) the minimization of the number of explanatory variables $\left(X_{j}\right)$ for reducing the complexity of the model.

From the starting database that includes the set of variables detected according to the data available, the technique allows for extrapolating the selling price function, making explicit the factors that influence the values. In particular, EPR-MOGA is a hybrid datadriven technique that combines numerical and symbolic regression methods through polynomial structures $[61,62]$. The implementation procedure consists of two main phases. In the first step, the search is performed to identify the model structure by generating a set of polynomial expressions. In the second one, the classical (numerical) regression method is used in order to estimate the polynomial coefficient values. In this sense, the main goal of EPR-MOGA is to find the best price function as a combination of independent variable vectors by implementing a regression with the least squares method aimed at generating the value of the coefficients of each variable, elevated by the proper exponents $[63,64]$.

The generic expression of the polynomial equation generated by EPR is represented by Equation (1), which describes a generic nonlinear model structure:

$$
Y=a_{0}+\sum_{i=1}^{n}\left[a_{i} \cdot\left(X_{1}\right)^{(i, 1)} \cdot \ldots \cdot\left(X_{j}\right)^{(i, j)} \cdot f\left(\left(X_{1}\right)^{(i, j+1)} \cdot \ldots \cdot\left(X_{j}\right)^{(i, 2 j)}\right)\right]
$$

Each equation element is explained below: $n$ is the number of additive terms, $a_{0}$ represents the constant additive term, $a_{i}$ are numerical coefficients to be assessed, $X_{j}$ are candidate explanatory variables, $(i, l)$-with $l=(1, \ldots, 2 j)$-is the exponent of the $l$-th input within the $i$-th term in Equation (1), $f$ is a function selected by the user. The exponents $(i, l)$ are also selected by the user from a set of real numbers.

The EPR-MOGA technique allows to generate a set of models; the quantity and the complexity of the solutions depend on the maximum terms number and on the possible exponents defined by the user.

Each polynomial expression generated by the EPR-MOGA technique is characterized by a specific statistical performance level. In this sense, the statistical accuracy of each model returned following the EPR-MOGA implementation is checked through its Coefficient of Determination (COD), which ranges between 0 and 1, reported in Equation (2):

$$
\operatorname{COD}=1-\frac{N-1}{N} \cdot \frac{\sum_{N}\left(y_{\text {estimated }}-y_{\text {detected }}\right)^{2}}{\sum_{N}\left(y_{\text {detected }}-\text { mean }\left(y_{\text {detected }}\right)\right)^{2}}
$$

where $y_{\text {estimated }}$ are the values of the dependent variable assessed by the method, $y_{\text {detected }}$ are the collected values of the dependent variable, $N$ is the sample size in analysis.

The model statistical accuracy is higher when the COD is close to the value $100 \%$ and, therefore, the user will choose a model characterized by a high COD level. In this regard, it should be outlined that the user choice is linked not only to the statistical performance of the model, but also to the empirical evidence of the functional relationships between explanatory variables (independent variables) and the selling prices (dependent variables).

\section{Application of the Method}

With reference to the four samples related to the four municipal areas in which the city of Bari is divided according to OMI, in the present research the EPR-MOGA technique implemented the generic model mathematical structure shown in Equation (1) with no function $f$ considered, so that the technique chose the best one and the algebraic expression was not excessively complicated.

Taking into account several study outputs [65,66], Pr (the dependent variable) is represented by the natural logarithm of the total selling price $(\mathrm{Y}=\ln (\operatorname{Pr}))$. 
The log-linear model was used as it is characterized by many attractive advantages $[67,68]$. Moreover, the log-linear form partially mitigates a common form of heteroskedasticity.

Each additive monomial term of the polynomial expressions generated by EPR-MOGA is a combination of the selected explanatory variables (inputs of the model) raised to the proper exponents.

For each EPR-MOGA application, the maximum number $n$ of additive terms is equal to eight in order to avoid a high complexity of model functional form and to allow an immediate interpretation of the results. It is evident that a larger number of terms in the equation complicates the analysis' functional correlations and the verification of the empirical evidence with the expected outputs. The candidate exponents belong to the range $(0 ; 0.5 ; 1 ; 2)$ in order to have a sufficiently wide set of solutions able to describe the phenomenon of the formation of selling prices and, at the same time, to avoid an excessive complexity of the mathematical forms. In fact, the exponent equal to zero value nullifies the variable influence and the exponent equal to unit value corresponds to the "pure" explanatory variable, whereas the exponents equal to 0.5 and 2 allow for considering functional quadratic-type forms.

The implementation of the EPR-MOGA technique was carried out four times (one for each study sample) including the same initial conditions (maximum number of additive terms, range candidate exponents) in order to obtain a model for each municipal OMI area of the city of Bari and to compare the outputs.

For each elaboration of EPR-MOGA, several models were generated. Table 2 shows the four equations selected (a model for the OMI central area, one for the semi-central area, one for the peripheral area and, finally, one for the suburban area). For each of them, the statistical accuracy of the outputs in terms of COD is indicated in Table 2.

Table 2. Models generated by EPR-MOGA implementation for each municipal OMI areas of the city of Bari.

\begin{tabular}{|c|c|c|}
\hline Municipal OMI Area & Model & $\operatorname{COD}(\%)$ \\
\hline Central & $\begin{array}{c}-2.1364 \cdot \mathrm{Dl}^{0.5}+2.0268 \cdot \mathrm{Sc} \cdot \mathrm{Dl}^{0.5} \cdot \mathrm{Ld}+3.2642 \cdot \mathrm{A} \cdot \mathrm{Ds}+ \\
+1.555 \cdot \mathrm{L}^{0.5}+4.4836 \cdot \mathrm{S}^{0.5}-6.9297 \cdot \mathrm{S}^{0.5} \cdot \mathrm{L}^{0.5} \cdot \mathrm{Ds}^{0.5} \cdot \mathrm{Ld}^{0.5}+9.4094\end{array}$ & 86.73 \\
\hline Semi-central & $\begin{array}{c}+33.7673 \cdot \mathrm{Sc}^{0.5} \cdot \mathrm{Dl}^{2} \cdot \mathrm{Ds}^{0.5} \cdot \mathrm{Qn}^{2}+0.34205 \cdot \mathrm{P}^{0.5} \cdot \mathrm{Sf}^{0.5}- \\
+28.409 \cdot \mathrm{P}^{0.5} \cdot \mathrm{Dl}^{2} \cdot \mathrm{Dv}^{0.5} \cdot \mathrm{Qn}^{2} \cdot \mathrm{Ld}^{0.5}+2.0779 \cdot \mathrm{L}^{0.5}- \\
+2.0641 \cdot \mathrm{L} \cdot \mathrm{Ld}^{0.5}+0.56217 \cdot \mathrm{B}^{0.5} \cdot \mathrm{A}^{2} \cdot \mathrm{Sc}^{2} \cdot \mathrm{T}^{0.5}+3.6085 \cdot \mathrm{S}^{0.5}- \\
+4.9704 \cdot \mathrm{S}^{2} \cdot \mathrm{B} \cdot \mathrm{Sc} \cdot \mathrm{Dl}^{0.5} \cdot \mathrm{Dt}^{0.5}+9.2473\end{array}$ & 83.15 \\
\hline Peripheral & $\begin{array}{c}+2.2214 \cdot \mathrm{Dv}^{0.5} \cdot \mathrm{Ds} \cdot \mathrm{Qn}+0.54754 \cdot \mathrm{Sc}^{0.5} \cdot \mathrm{Sa}^{0.5}+0.83222 \cdot \mathrm{P}^{0.5} \\
\quad \cdot \mathrm{Ds}+0.18301 \cdot \mathrm{A}^{0.5}+4.5316 \cdot \mathrm{L}^{0.5} \cdot \mathrm{Sf}^{0.5} \cdot \mathrm{Dt}^{0.5} \cdot \mathrm{Qn} \cdot \mathrm{Ld}^{2}- \\
+2.5508 \cdot \mathrm{L}^{0.5} \cdot \mathrm{P}^{0.5} \cdot \mathrm{Sf}^{0.5} \cdot \mathrm{Dt}+5.2405 \cdot \mathrm{S}^{0.5}-2.0766 \cdot \mathrm{S} \cdot \mathrm{Ld}+8.6718\end{array}$ & 83.14 \\
\hline Suburban & $\begin{array}{c}+1.6114 \cdot \mathrm{Dl}^{0.5}+2.1545 \cdot \mathrm{Dl} \cdot \mathrm{Dv}+1.8803 \cdot \mathrm{Sc} \cdot \mathrm{Dv}+0.19514 \cdot \\
\mathrm{A}^{0.5}+8.3442 \cdot \mathrm{S}^{0.5}-5.2521 \cdot \mathrm{S}+7.5065\end{array}$ & 81.71 \\
\hline
\end{tabular}

It should be noted that each model is characterized by a high statistical accuracy level $(\mathrm{COD}=+86.73 \%$ for the OMI central area model,$+83.15 \%$ for the semi-central one, $+83.14 \%$ for the OMI peripheral area equation and $+81.71 \%$ for the model related to the suburban area) and includes a large number of influential factors (seven for the central area study sample, fourteen for the semi-central area sample, twelve for the peripheral one, five for the suburban area study sample).

Furthermore, for all models the algebraic structure of the equations, i.e., the complexity of the terms that compose them, does not allow an immediate interpretation of the functional relationships among the variables. In fact, each term of the equations is a combination of different variables that occur several times in the same model.

Therefore, the functional correlations of the $i$-th independent explanatory variable with the variation of the selling prices were explicated by means of a simplified approach that considers the other variable values equal to the average values of the starting database (value 1 or 0 if the factor is a dummy variable). Moreover, the approach provides the analy- 
sis of the changes in value of the assessed variations of selling prices in correspondence of each $i$-th variable in the admissible range of its corresponding sample values.

In particular, for each municipal OMI area Tables 3-6 show the functional relationships typology (direct or negative) found for each explanatory variable selected by the four models. For each variable, the marginal influence on selling prices in terms of average percentage variation obtained in correspondence of the passage from a level to the next one is reported. From the analysis of functional correlations between influential factors selected by the models and market prices, the empirical evidence of the coefficient signs is verified for all municipal OMI areas of the city of Bari. Thus, for each explanatory variable the consistency of the links with the expected phenomena is verified.

Table 3. Total selling price average percentage variation for the variables chosen by the model for the OMI central area of the city of Bari.

\begin{tabular}{lccc}
\hline \multicolumn{1}{c}{$\begin{array}{c}\text { Variable } \\
\text { Denomination }\end{array}$} & $\begin{array}{c}\text { Variable } \\
\text { Acronym }\end{array}$ & $\begin{array}{c}\text { Functional } \\
\text { Correlation }\end{array}$ & $\begin{array}{c}\text { Average Percentage } \\
\text { Variation (\%) }\end{array}$ \\
\hline Distance from the waterfront & $\mathrm{Dl}$ & negative & -3.56 \\
\hline Maintenance conditions & Sc & direct & 20.22 \\
\hline $\begin{array}{l}\text { Sound level in the street where } \\
\text { the property is located }\end{array}$ & Ld & negative & -3.31 \\
\hline Lift & $\mathrm{A}$ & direct & 30.95 \\
\hline $\begin{array}{l}\text { Distance from the nearest } \\
\text { railway station }\end{array}$ & Ds & negative & -3.01 \\
\hline Floor level & $\mathrm{L}$ & direct & 2.67 \\
\hline Size & $\mathrm{S}$ & direct & 22.80 \\
\hline
\end{tabular}

Table 4. Total selling price average percentage variation for the variables chosen by the model for the OMI semi-central area of the city of Bari.

\begin{tabular}{lccc}
\hline \multicolumn{1}{c}{$\begin{array}{c}\text { Variable } \\
\text { Denomination }\end{array}$} & $\begin{array}{c}\text { Variable } \\
\text { Acronym }\end{array}$ & $\begin{array}{c}\text { Functional } \\
\text { Correlation }\end{array}$ & $\begin{array}{c}\text { Average Percentage } \\
\text { Variation (\%) }\end{array}$ \\
\hline Maintenance conditions & Sc & direct & 19.49 \\
\hline Distance from the waterfront & Dl & direct & 0.63 \\
\hline $\begin{array}{l}\text { Distance from the nearest railway } \\
\text { station }\end{array}$ & Ds & direct & 2.48 \\
\hline Perceived environmental quality level & Qn & direct & 0.52 \\
\hline Presence of parking & P & direct & 4.3 \\
\hline $\begin{array}{l}\text { Maintenance conditions of the building } \\
\text { facades adjacent to the property }\end{array}$ & Sf & direct & 9.01 \\
\hline $\begin{array}{l}\text { Distance from the nearest public green } \\
\text { space }\end{array}$ & Dv & negative & -1.14 \\
\hline $\begin{array}{l}\text { Sound level in the street where the } \\
\text { property is located }\end{array}$ & Ld & negative & -3.46 \\
\hline Floor level & L & parabolic & 0.77 \\
\hline Bathroom number & B & direct & 0.09 \\
\hline $\begin{array}{l}\text { Lift } \\
\begin{array}{l}\text { Road private and public vehicular traffic } \\
\text { level }\end{array}\end{array}$ & T & direct & 8.85 \\
\hline $\begin{array}{l}\text { Size } \\
\text { Distance from the nearest highway }\end{array}$ & Dt & direct & 3.08 \\
\hline
\end{tabular}


Table 5. Total selling price average percentage variation for the variables chosen by the model for the OMI peripheral area of the city of Bari.

\begin{tabular}{lccc}
\hline \multicolumn{1}{c}{$\begin{array}{c}\text { Variable } \\
\text { Denomination }\end{array}$} & $\begin{array}{c}\text { Variables } \\
\text { Acronym }\end{array}$ & $\begin{array}{c}\text { Functional } \\
\text { Correlation }\end{array}$ & $\begin{array}{c}\text { Average Percentage } \\
\text { Variation (\%) }\end{array}$ \\
\hline $\begin{array}{l}\text { Distance from the nearest public } \\
\text { green space }\end{array}$ & Dv & direct & 3.73 \\
\hline $\begin{array}{l}\text { Distance from the nearest railway } \\
\text { station }\end{array}$ & Ds & direct & 7.11 \\
\hline $\begin{array}{l}\text { Perceived environmental quality } \\
\text { level }\end{array}$ & Qn & direct & 4.73 \\
\hline $\begin{array}{l}\text { Maintenance conditions } \\
\text { Maintenance conditions of the public } \\
\text { spaces adjacent to the property }\end{array}$ & Sc & direct & 8.69 \\
\hline $\begin{array}{l}\text { Presence of the parking } \\
\text { Lift }\end{array}$ & P & direct & 11.26 \\
\hline Floor level & A & direct & 3.59 \\
\hline $\begin{array}{l}\text { Maintenance conditions of the } \\
\text { building facades adjacent to the } \\
\text { property }\end{array}$ & L & direct & 16.72 \\
\hline Distance from the nearest highway & Dt & parabolic & 1.38 \\
\hline $\begin{array}{l}\text { Sound level in the street where the } \\
\text { property is located }\end{array}$ & Ld & negative & -2.85 \\
\hline Size & S & direct & -2.47 \\
\hline
\end{tabular}

Table 6. Total selling prices average percentage variation for the variables chosen by the model for the OMI suburban area of the city of Bari.

\begin{tabular}{lccc}
\hline \multicolumn{1}{c}{$\begin{array}{c}\text { Variable } \\
\text { Denomination }\end{array}$} & $\begin{array}{c}\text { Variables } \\
\text { Acronym }\end{array}$ & $\begin{array}{c}\text { Functional } \\
\text { Correlation }\end{array}$ & $\begin{array}{c}\text { Average Percentage } \\
\text { Variation (\%) }\end{array}$ \\
\hline Distance from the waterfront & $\mathrm{Dl}$ & direct & 5.52 \\
\hline $\begin{array}{l}\text { Distance from the nearest public } \\
\text { green space }\end{array}$ & $\mathrm{Dv}$ & direct & 1.2 \\
\hline Maintenance conditions & Sc & direct & 17.74 \\
\hline Lift & $\mathrm{A}$ & direct & 17.73 \\
\hline Size & $\mathrm{S}$ & direct & 0.88 \\
\hline
\end{tabular}

It should be pointed out that for the suburban area the variable Ld was not selected by the model as an influencing factor on selling prices. Therefore, the following considerations related to the noise pollution incidence on property prices exclusively refer to the remaining three OMI areas (central, semi-central, peripheral) of the city of Bari.

Thus, with reference to the sound level detected in the street where the property is located (Ld), the graphs in Figures 7-9 show a negative correlation between the unit selling prices and the Ld label for the central, semi-central and peripheral municipal areas. Furthermore, in each Figure the percentage variations of the total selling prices for the noise pollution class rating for the three OMI areas of the city of Bari are reported. 


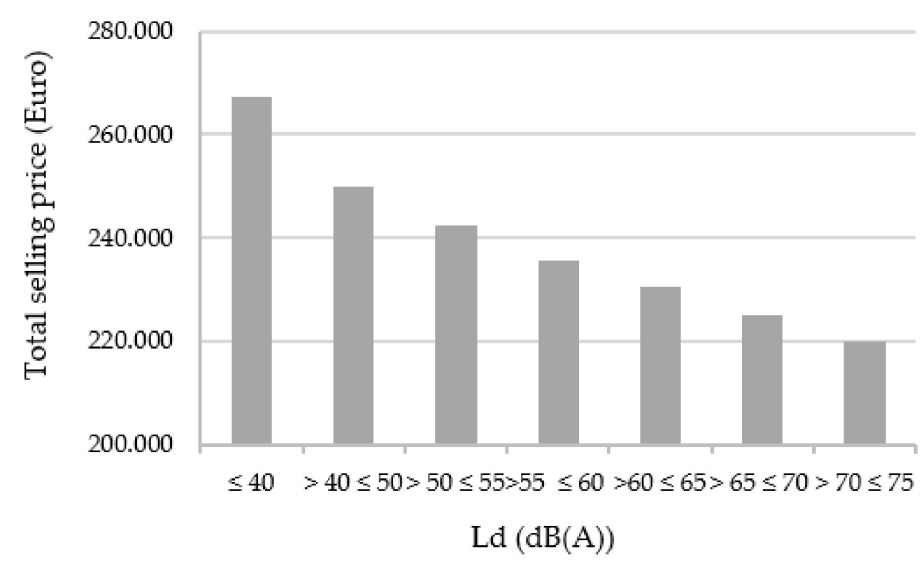

\begin{tabular}{cc}
\hline Rating & $\begin{array}{c}\text { Percentage variations of } \\
\text { the total selling prices }\end{array}$ \\
\hline$\leq 40$ & \\
$>40-\leq 50$ & $-6.88 \%$ \\
$>50-\leq 55$ & $-3.15 \%$ \\
$>55-\leq 60$ & $-2.87 \%$ \\
$>60-\leq 65$ & $-2.26 \%$ \\
$>65-\leq 70$ & $-2.45 \%$ \\
$>70-\leq 75$ & $-2.25 \%$ \\
\hline
\end{tabular}

Figure 7. Functional relationship between the Ld label and the prices and percentage variations for the noise pollution class rating for the OMI central area of the city of Bari.

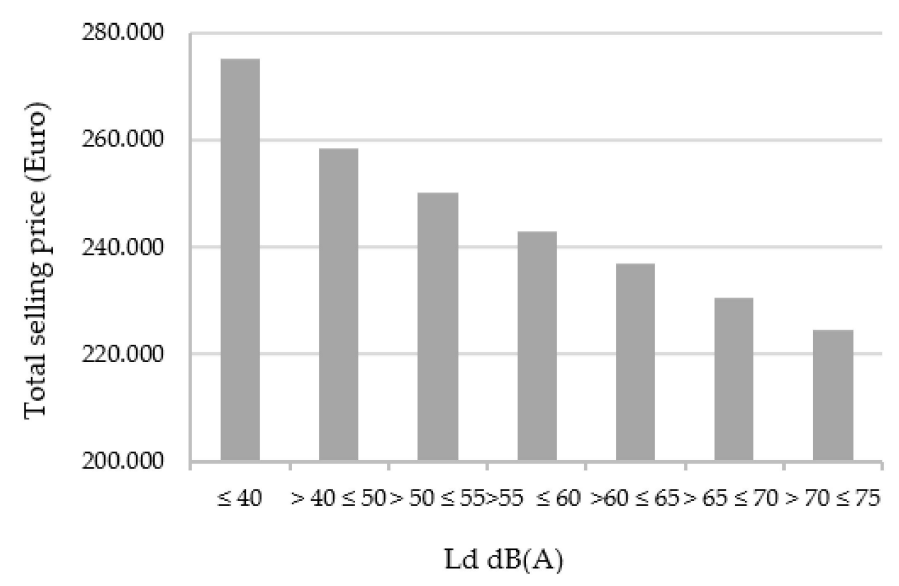

\begin{tabular}{cc}
\hline Rating & $\begin{array}{c}\text { Percentage variations of } \\
\text { the total selling prices }\end{array}$ \\
\hline$\leq 40$ & \\
$>40-\leq 50$ & $-6.51 \%$ \\
$>50-\leq 55$ & $-3.19 \%$ \\
$>55-\leq 60$ & $-3.04 \%$ \\
$>60-\leq 65$ & $-2.49 \%$ \\
$>65-\leq 70$ & $-2.81 \%$ \\
$>70-\leq 75$ & $-2.70 \%$ \\
\hline
\end{tabular}

Figure 8. Functional relationship between the Ld label and the prices and percentage variations for the noise pollution class rating for the OMI semi-central area of the city of Bari.

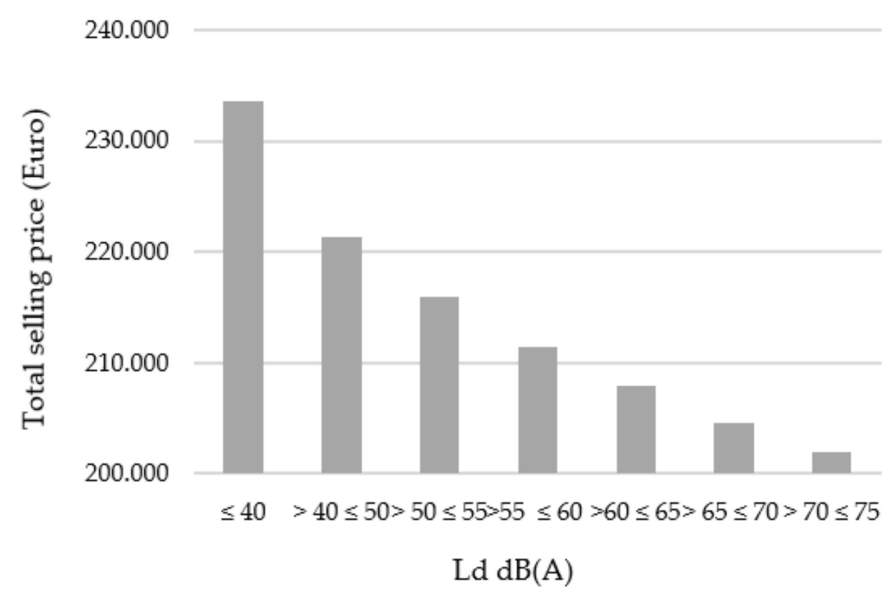

\begin{tabular}{cc}
\hline Rating & $\begin{array}{c}\text { Percentage variations of } \\
\text { the total selling prices }\end{array}$ \\
\hline$\leq 40$ & \\
$>40-\leq 50$ & $-5.49 \%$ \\
$>50-\leq 55$ & $-2.49 \%$ \\
$>55-\leq 60$ & $-2.19 \%$ \\
$>60-\leq 65$ & $-1.64 \%$ \\
$>65-\leq 70$ & $-1.64 \%$ \\
$>70-\leq 75$ & $-1.34 \%$ \\
\hline
\end{tabular}

Figure 9. Functional relationship between the Ld label and the prices and percentage variations for the noise pollution class rating for the OMI peripheral area of the city of Bari.

With regard to the aim of the study, the results obtained for the variable Ld - the sound level detected in the street where the property is located-allow for obtaining interesting considerations. 
Firstly, as already mentioned, the variable Ld is included in the models related to the OMI central area, semi-central and peripheral municipal areas of the city of Bari, whereas it is excluded from the variables selected by the EPR-MOGA technique in the OMI suburban area.

This result confirms an expected phenomenon: the central and semi-central municipal OMI areas are affected by a higher noise pollution level compared to the peripheral and suburban trade areas, for which a lower noise pollution is detected. The Strategic Noise Map of the city of Bari, reported in Figure 6, attests that, excluding the airport area characterized by a relevant noise pollution level, the other portions of the peripheral and suburban of city of Bari show a sound level $(\mathrm{Ld})$ between $<40 \mathrm{~dB}(\mathrm{~A})$ and $55 \mathrm{~dB}(\mathrm{~A})$. In this sense, the central and semi-central municipal areas are characterized by a larger number of leisure and commercial activities that cause higher loudness level, especially in the evening hours, instead of peripheral and suburban areas in which there are a greater amount of green or empty urban spaces that determine lower noise pollution levels.

With reference to the outputs obtained, the average percentage decrease in the selling price corresponding to a variation from one $\mathrm{Ld}$ level to the next one is almost constant for the OMI central area $(-3.31 \%)$ and for the OMI semi-central area $(-3.46 \%)$ of the city of Bari. Conversely, for the peripheral area, the average percentage decrease in the housing price corresponding to a passage from a Ld level to the next one is lower and equal to $-2.47 \%$. This confirms the lower influence given by the factor related to the noise pollution on selling prices in the municipal OMI area in which the pollution is minor, due to a less levels of road traffic and industrial traffic and less of a preference for recreational activities. For the suburban municipal area, the model generated by the EPR-MOGA technique implementation does not include the variable Ld among the influencing factors on selling prices. Thus, it is evident that a lower noise pollution level (average sound level Ld for the central area is equal to $64.8 \mathrm{~dB}(\mathrm{~A})$, whereas the sound level Ld for the suburban area is equal to $57.02 \mathrm{~dB}(\mathrm{~A})$ ) corresponds to a less significant effect of the acoustic factor in the selling price formation.

For each study sample, in the Table 7 the percentage variations in the total selling residential prices, from the best situation-i.e., rating $1(<40 \mathrm{~dB}(\mathrm{~A}))$ - to the worst onerating 7 (>70 and $\leq 75 \mathrm{~dB}(\mathrm{~A})$ )-are reported.

Table 7. Percentage variation in the market prices from rating 1 to rating 7 for the four municipal OMI areas of the city of Bari.

\begin{tabular}{cc}
\hline Municipal OMI Area & Average Percentage Variation from Rating $\mathbf{1}$ to Rating $\mathbf{7 ~ ( \% )}$ \\
\hline Central & -21.50 \\
\hline Semi-central & -22.56 \\
\hline Peripheral & -15.67 \\
\hline Suburban & - \\
\hline
\end{tabular}

Finally, the average unitary contribution of the explanatory variable Ld on the housing prices for the four OMI areas of the city of Bari and in percentage terms is shown in Table 8 .

Table 8. Average unitary influence of the variable Ld for the four municipal OMI areas of the city of Bari.

\begin{tabular}{cc}
\hline Municipal OMI Area & Average Unitary Contribution of Ld (\%) \\
\hline Central & -0.56 \\
\hline Semi-central & -0.58 \\
\hline Peripheral & -0.42 \\
\hline Suburban & - \\
\hline
\end{tabular}




\section{Conclusions}

The increase of public and private road traffic, loud recreation activities and industrial activities located in residential areas in European and U.S. cities has led to a relevant growth of the noise pollution level. In particular, the road networks cover entire cities, undergoing and connecting the residential, commercial and directional districts. It is noted that the road noise is one of the greatest sources of discomfort [69] because an increasing congestion level characterizes the traffic on the city street. Therefore, currently the environmental aspects play a fundamental role in the urban policies aimed to define strategies for the reduction of noise pollution and, at the same time, for the development of more sustainable cities characterized by a high urban quality level [70-72]. In this sense, the noise levels may directly and strongly influence the market residential prices.

With reference to four study samples composed of two hundred residential properties sold in 2017-2019 and located in the four municipal OMI areas in which the city of Bari (Southern Italy) is divided (central, semi-central, peripheral and suburban), the aim of the present paper was double: (i) to investigate the presence and, eventually, the influence of noise among the most influencing factors on property prices and (ii) to compare the contribution of acoustic components on selling prices in the four municipal OMI areas according to the different features of each in terms of the traffic congestion level and presence of loud activities. For each study sample, the total market prices and the relevant influential factors for their formation were detected. An econometric technique was implemented for determining the contribution of each factor selected and for analyzing the influence of noise pollution factor on property prices. For each municipal OMI area, a model was selected among those generated by the technique, and the functional correlations between the influential factors and the market prices were analyzed. With reference to the acoustic component, the models for the central, semi-central and peripheral areas included the variable related to the sound level calculated in the street where the property was located, whereas for the suburban area this variable was not selected.

Furthermore, for the central, semi-central and peripheral areas, a negative link between the noise level and the housing prices was noted, which confirms that a building's location characterized by a noise high level causes a reduction in residential market values. In particular, the average percentage decrease of prices given by a high noise pollution level was similar for the central and OMI semi-central areas of the city of Bari, and it was lower for the peripheral one. Thus, the results of the study confirm that the impact of noise on the decisions made by real estate buyers is less relevant in the urban area where the acoustic pollution is weaker.

This analysis could represent a useful tool for public administration to orient specific urban interventions aimed to create acoustic comfort in urban spaces and to promote measures for the reduction of the noise pollution, e.g., introduction of limited traffic or pedestrian areas, planning of ecological days, provision of public services for sustainable and slow mobility and diffusion of bike sharing systems.

The present research has intended to focalize the relevance of the issue. In recent years a higher attention has been focused on the housing aspects able to increase the well-being of inhabitants. Furthermore, strong awareness-raising actions and information campaigns have been developed in order to promote the realization of domestic spaces characterized by high quality levels. In this sense, the main three topics sponsored concern energy saving, seismic safety and noise reduction. The definition of incentives-also in fiscal and economic terms-aimed at stimulating the housing comfort improvement contributes to the awareness growth toward residential property factors redevelopment and ex-novo realization. In the Italian context, the variables associated with the acoustic component vary among different urban territories because of urban morphology (e.g., building typology, density of the property asset, houses proximity, green barriers, etc.). In particular, with reference to the present analysis, the factors considered were selected taking into account the indications of the local market operators that reported the acoustic factor as one of the most influencing in the buyers' decision process. This attests to the prominence of domestic 
space comfort aspects in the current specific market of the city of Bari. It should be added that the Covid-19 pandemic lockdown has raised the attention for indoor noise even more due to (i) the smart working spread, (ii) the functional adaptation of housing spaces for a longer duration of home living, (iii) the temporary reduction of external noise (cars, trains, airplanes, people, etc.). Therefore, this contingence has determined a higher appreciation for specific residential property factors that probably in the past were not so influential.

Further insight into the research may address the implementation of the econometric technique to other national or international territorial contexts in order to analyze the influence of noise pollution on selling prices in different urban areas and to compare the results.

Moreover, the study may be developed through the investigation of the relationship between the environmental factors related to the acoustic component and the floor level on which the property is located. In this sense, the floor level could have a significant moderating effect on the external effect of road traffic and, at the same time, the sound pressure deriving from the road traffic could drop significantly with the increase of floor level [73]. It could be interesting to implement the econometric technique using the noise level as a dependent variable and the floor level as one of the factors that influences its value in order to define a direct functional link between the two characteristics.

Supplementary Materials: The following are available online at https:/ / www.mdpi.com/article/ 10.3390 /buildings11050213/s1, Table S1. Descriptive statistics of the variables for the municipal OMI central area; Table S2. Descriptive statistics of the variables for the municipal OMI semi-central area; Table S3. Descriptive statistics of the variables for the municipal OMI peripheral area; Table S4. Descriptive statistics of the variables for the municipal OMI suburban area.

Author Contributions: The contribution is the result of the joint work of the authors. In particular: conceptualization, P.M., F.T., M.D.; methodology, P.M., F.D.L., F.T.; validation, P.M.; formal analysis, F.T.; investigation, M.D.; data curation, F.D.L.; writing-review and editing, F.D.L., F.T.; supervision, P.M. All authors have read and agreed to the published version of the manuscript.

Funding: This research received no external funding.

Institutional Review Board Statement: Not applicable.

Informed Consent Statement: Not applicable.

Data Availability Statement: The data is contained within the article.

Conflicts of Interest: The authors declare no conflict of interest.

\section{References}

1. European Commission. Directive 2002/49/EC of the European Parliament and of the Council of 25 June 2002 Relating to the Assessment and Management of Environmental Noise-Declaration by the Commission in the Conciliation Committee on the Directive Relating to the Assessment and Management of Environmental Noise. Off. J. Eur. Communities 2002, 189, 12-25.

2. Ozdemir, B.; Bayramoglu, E.; Demirel, O. Noise Pollution and Human Health in Trabzon Parks. Stud. Ethno Med. 2014, 8, 127-134. [CrossRef]

3. Önder, S.; Akay, A. Reduction of Traffic Noise Pollution Effects by Using Vegetation, Turkey'Sample. J. Eng. Econ. Dev. 2015, 2, 23.

4. Oroke, A.M.; Sarihan, E.; Ogbuene, E.B.; Ani, C. Assessment of Noise Pollution Level in Abakaliki Metropolis, Ebonyi State Nigeria. Theor. Empir. Res. Urban Manag. 2020, 15, 75-83.

5. World Health Organization. Burden of Disease from Environmental Noise: Quantification of Healthy Life Years Lost in Europe; World Health Organization, Regional Office for Europe: Copenhagen, Denmark, 2011.

6. Bello, J.P.; Silva, C.; Nov, O.; DuBois, R.L.; Arora, A.; Salamon, J.; Doraiswamy, H. SONYC: A system for the monitoring, analysis and mitigation of urban noise pollution. Commun. ACM 2019, 62, 68-77. [CrossRef]

7. Maibach, M.; Schreyer, C.; Sutter, D.; Van Essen, H.P.; Boon, B.H.; Smokers, R.; Bak, M. Report Produced within the Study Internalisation Measures and Policies for All External Cost of Transport (IMPACT). In Handbook on Estimation of External Costs in the Transport Sector; Version 1.1; European Commission DG TREN: Delft, CE, The Netherlands, 2008; Available online: http:/ / www.europadecentraal.nl/documents/dossiers/Transport/2008_01_15_handbook_external_cost_en.pdf (accessed on 10 March 2020).

8. Mizutani, F.; Suzuki, Y.; Sakai, H. Estimation of Social Costs of Transport in Japan. Urban Stud. 2011, 48, 3537-3559. [CrossRef] 
9. European Environment Agency Number of Europeans Exposed to Harmful Noise Pollution Expected to Increase. 2020. Available online: www.eea.europa.eu (accessed on 27 February 2020).

10. World Health Organization. Environmental Noise Guidelines for the European Region. 2018. Available online: www.euro.who.int (accessed on 15 March 2020).

11. UN. Transforming our World: The 2030 Agenda for Sustainable Development. Available online: https://www.un.org/ga/ search/view_doc.asp?symbol=A/RES/70/1\&Lang=E (accessed on 17 July 2020).

12. Agenzia Delle Entrate. Available online: http://www.agenziaentrate.gov.it/ (accessed on 25 January 2020).

13. Jariwala, H.J.; Syed, H.S.; Pandya, M.J.; Gajera, Y.M. Noise Pollution \& Human Health: A Review. Indoor Built Environ. 2017, 1-4. Available online: https://www.researchgate.net/profile/Hiral-Jariwala/publication/319329633_Noise_Pollution_Human_ Health_A_Review/links/59a54434a6fdcc773a3b1c49/Noise-Pollution-Human-Health-A-Review.pdf (accessed on 10 April 2020).

14. Aluko, E.; Nna, V. Impact of Noise Pollution on Human Cardiovascular System. Int. J. Trop. Dis. Health 2015, 6, 35-43. [CrossRef]

15. Ozdenerol, E.; Huang, Y.; Javadnejad, F.; Antipova, A. The Impact of Traffic Noise on Housing Values. J. Real Estate Pract. Educ. 2015, 18, 35-54. [CrossRef]

16. Franck, M.; Eyckmans, J.; De Jaeger, S.; Rousseau, S. Comparing the impact of road noise on property prices in two separated markets. J. Environ. Econ. Policy 2015, 4, 15-44. [CrossRef]

17. Beimer, W.; Maennig, W. Noise effects and real estate prices: A simultaneous analysis of different noise sources. Transp. Res. Part D Transp. Environ. 2017, 54, 282-286. [CrossRef]

18. Li, W.; Saphores, J.D. Assessing impacts of freeway truck traffic on residential property values: Southern California Case Study. Transp. Res. Rec. 2012, 2288, 48-56. [CrossRef]

19. Guijarro, F. Assessing the Impact of Road Traffic Externalities on Residential Price Values: A Case Study in Madrid, Spain. Int. J. Environ. Res. Public Health 2019, 16, 5149. [CrossRef] [PubMed]

20. Hogan, C.M. Analysis of highway noise. Water Air Soil Pollut. 1973, 2, 387-392. [CrossRef]

21. Swoboda, A.; Nega, T.; Timm, M. Hedonic analysis over time and space: The case of house prices and traffic noise. J. Reg. Sci. 2015, 55, 644-670. [CrossRef]

22. Mínguez, R.; Montero, J.-M.; Fernández-Avilés, G. Measuring the impact of pollution on property prices in Madrid: Objective versus subjective pollution indicators in spatial models. J. Geogr. Syst. 2013, 15, 169-191. [CrossRef]

23. Del Giudice, V.; De Paola, P. The Effects of Noise Pollution Produced by Road Traffic of Naples Beltway on Residential Real Estate Values. Appl. Mech. Mater. 2014, 587-589, 2176-2182. [CrossRef]

24. Amrusch, P. The impact of urban traffic and environmental conditions on the housing market: An analysis of Italian and Slovenian urban areas. WIT Trans. Built Environ. 2005, 77. [CrossRef]

25. Ottoz, E.; Pavese, P.; Sella, L. The effect of Movida on residential property prices: An example from Turin. In Proceedings of the Pedestrians, Urban Spaces and Health; Apple Academic Press: Palm Bay, FL, USA, 2020; pp. 170-174.

26. D'Arcangelo, F.M.; Percoco, M. Housing rent and road pricing in Milan: Evidence from a geographical discontinuity approach. Transp. Policy 2015, 44, 108-116. [CrossRef]

27. Blanco, J.C.; Flindell, I. Property prices in urban areas affected by road traffic noise. Appl. Acoust. 2011, 72, 133-141. [CrossRef]

28. Paunović, K.; Belojević, G.; JakovljeviĆ, B. Noise annoyance is related to the presence of urban public transport. Sci. Total. Environ. 2014, 481, 479-487. [CrossRef] [PubMed]

29. Chang, J.S.; Kim, D.-J. Hedonic estimates of rail noise in Seoul. Transp. Res. Part D Transp. Environ. 2013, 19, 1-4. [CrossRef]

30. Bureau, B.; Glachant, M. Évaluation de l'impact des politiques. Econ. Prévis. 2010, 192, 27-44. [CrossRef]

31. EEA, European Environment Agency. Technical Report No 11/2010 EEA. Good Practice Guide on Noise Exposure and Potential Health Effects. 2010. Available online: http:/ / www.eea.europa.eu/publications/goodpractice-guide-on-noise (accessed on 7 February 2020).

32. Brandt, S.; Maennig, W. Road noise exposure and residential property prices: Evidence from Hamburg. Transp. Res. Part D Transp. Environ. 2011, 16, 23-30. [CrossRef]

33. Arsenio, E.; Bristow, A.L.; Wardman, M. Stated choice valuations of traffic related noise. Transp. Res. Part D Transp. Environ. 2006, 11, 15-31. [CrossRef]

34. Bateman, I.; Day, B.; Lake, I.; Lovett, A. The Effects of Road Traffic on Residential Property Values: A Literature Review and Hedonic Pricing Study; Technical Report; University of East Anglia: Norwich, UK; Economic \& Social Research Council: Swindon, UK; University College London: London, UK, 2001.

35. Garrod, G.D.; Scarpa, R.; Willis, K.G. Estimating The Benefits of Traffic Calming on Through Routes: A Choice Experiment Approach. SSRN Electron. J. 2003, 36, 211-231. [CrossRef]

36. Navrud, S. The economic value of noise within the European Union-A review and analysis of studies. Acústica 2004, 14-17. Available online: http:/ / citeseerx.ist.psu.edu/viewdoc/download?doi=10.1.1.582.6811\&rep=rep1\&type=pdf (accessed on 26 April 2020).

37. Nelson, J.P. Highway noise and property values: A survey of recent evidence. J. Transp. Econ. Policy 1982, 16, 117-138.

38. Nelson, J.P. Meta-analysis of airport noise and hedonic property values. J. Transp. Econ. Policy 2004, 38, 1-27.

39. Andersson, H.; Jonsson, L.; Ögren, M. Property Prices and Exposure to Multiple Noise Sources: Hedonic Regression with Road and Railway Noise. Environ. Resour. Econ. 2009, 45, 73-89. [CrossRef] 
40. Wilhelmsson, M. The Impact of Traffic Noise on the Values of Single-family Houses. J. Environ. Plan. Manag. 2000, 43, 799-815. [CrossRef]

41. Rich, J.H.; Nielsen, O.A. Assessment of traffic noise impacts. Int. J. Environ. Stud. 2004, 61, 19-29. [CrossRef]

42. Duarte, C.M.; Tamez, C.G. Does noise have a stationary impact on residential values? J. Eur. Real Estate Res. 2009, 2, 259-279. [CrossRef]

43. Wen, H.; Gui, Z.; Zhang, L.; Hui, E.C. An empirical study of the impact of vehicular traffic and floor level on property price. Habitat Int. 2020, 97, 102132. [CrossRef]

44. Szczepańska, A.; Senetra, A.; Wasilewicz-Pszczółkowska, M. The Influence of Traffic Noise on Apartment Prices on the Example of a European Urban Agglomeration. Sustainability 2020, 12, 801. [CrossRef]

45. Kuehnel, N.; Moeckel, R. Impact of simulation-based traffic noise on rent prices. Transp. Res. Part D: Transp. Environ. 2020, 78, 102191. [CrossRef]

46. Szopińska, K.; Krajewska, M. Prices of Apartments in Relation to Noise Level in Poland. J. Civ. Eng. Arch. 2013, 7, 1189-1195. [CrossRef]

47. Ligus, M.; Peternek, P. Measuring Structural, Location and Environmental Effects: A Hedonic Analysis of Housing Market in Wroclaw, Poland. Procedia-Soc. Behav. Sci. 2016, 220, 251-260. [CrossRef]

48. Cellmer, R. Spatial analysis of the effect of noise on the prices and value of residential real estates. Geomat. Environ. Eng. 2011, 5, 13-28.

49. Iovine, A. La Revisione delle Rendite Delle Unità Immobiliari Urbane; Sistemi Editoriali: Naples, Italy, 2006; ISBN 9788851303464.

50. Bourassa, S.C.; Hoesli, M.; Peng, V.S. Do housing submarkets really matter? J. Hous. Econ. 2003, 12, 12-28. [CrossRef]

51. Grether, D.; Mieszkowski, P. Determinants of real estate values. J. Urban Econ. 1974, 1, 127-145. [CrossRef]

52. Vogiazas, S.; Alexiou, C. Determinants of Housing Prices and Bubble Detection: Evidence from Seven Advanced Economies. Atl. Econ. J. 2017, 45, 119-131. [CrossRef]

53. Égert, B.; Mihaljek, D. Determinants of House Prices in Central and Eastern Europe. Comp. Econ. Stud. 2007, 49, 367-388. [CrossRef]

54. Dziauddin, M.F.; Ismail, K.; Othman, Z. Analysing the local geography of the relationship between residential property prices and its determinants. Bull. Geogr. Socio-Econ. Ser. 2015, 28, 21-35. [CrossRef]

55. Zoppi, C.; Argiolas, M.; Lai, S. Factors influencing the value of houses: Estimates for the city of Cagliari, Italy. Land Use Policy 2015, 42, 367-380. [CrossRef]

56. Mbachu, J.I.; Lenono, N. Factors influencing market values of residential properties. In Proceedings of the Queensland University of Technology Research Week International Conference, QUT Research Week 2005, Brisbane, QLD, Australia, 4-8 July 2005.

57. Cui, N.; Gu, H.; Shen, T.; Feng, C. The Impact of Micro-Level Influencing Factors on Home Value: A Housing Price-Rent Comparison. Sustainability 2018, 10, 4343. [CrossRef]

58. Bourassa, S.; Cantoni, E.; Hoesli, M. Predicting House Prices with Spatial Dependence: A Comparison of Alternative Methods. J. Real Estate Res. 2010, 32, 139-160. [CrossRef]

59. ARPA Puglia. Available online: www.arpa.puglia.it (accessed on 14 December 2019).

60. Giustolisi, O.; Savic, D. Advances in data-driven analyses and modelling using EPR-MOGA. J. Hydroinform. 2009, 11, 225-236. [CrossRef]

61. Rezania, M.; Javadi, A.A.; Giustolisi, O. An evolutionary-based data mining technique for assessment of civil engineering systems. Eng. Comput. 2008, 25, 500-517. [CrossRef]

62. Morano, P.; Tajani, F.; Di Liddo, F.; Anelli, D. A Feasibility Analysis of The Refurbishment Investments in The Italian Residential Market. Sustainability 2020, 12, 2503. [CrossRef]

63. Tajani, F.; Morano, P.; Torre, C.M.; Di Liddo, F. An Analysis of the Influence of Property Tax on Housing Prices in the Apulia Region (Italy). Buildings 2017, 7, 67. [CrossRef]

64. Morano, P.; Rosato, P.; Tajani, F.; Manganelli, B.; Di Liddo, F. Contextualized Property Market Models vs. Generalized Mass Appraisals: An Innovative Approach. Sustainability 2019, 11, 4896. [CrossRef]

65. Cassel, E.; Mendelsohn, R. The choice of functional forms for hedonic price equations: Comment. J. Urban Econ. 1985, 18, 135-142. [CrossRef]

66. Lynch, A.K.; Rasmussen, D.W. Proximity, Neighbourhood and the Efficacy of Exclusion. Urban Stud. 2004, 41, 285-298. [CrossRef]

67. Malpezzi, S.; Chun, G.H.; Green, R.K. New Place-to-Place Housing Price Indexes for U.S. Metropolitan Areas, and Their Determinants. Real Estate Econ. 1998, 26, 235-274. [CrossRef]

68. Selim, H. Determinants of house prices in Turkey: Hedonic regression versus artificial neural network. Expert Syst. Appl. 2009, 36, 2843-2852. [CrossRef]

69. Liu, J.; Kang, J.; Luo, T.; Behm, H.; Coppack, T. Spatiotemporal variability of soundscapes in a multiple functional urban area. Landsc. Urban Plan. 2013, 115, 1-9. [CrossRef]

70. Guarini, M.R.; D'Addabbo, N.; Morano, P.; Tajani, F. Multi-Criteria Analysis in Compound Decision Processes: The AHP and the Architectural Competition for the Chamber of Deputies in Rome (Italy). Buildings 2017, 7, 38. [CrossRef]

71. Morano, P.; Tajani, F. The Transfer of Development Rights for the Regeneration of Brownfield Sites. Appl. Mech. Mater. 2013, 409-410, 971-978. [CrossRef] 
72. Morano, P.; Tajani, F. Break Even Analysis for the Financial Verification of Urban Regeneration Projects. Appl. Mech. Mater. 2013, 438-439, 1830-1835. [CrossRef]

73. Mak, C.M.; Leung, W.; Jiang, G. Measurement and prediction of road traffic noise at different building floor levels in Hong Kong. Build. Serv. Eng. Res. Technol. 2010, 31, 131-139. [CrossRef] 